\title{
Subcortical band heterotopia
}

INSERM

\section{Source}

INSERM. (1999). Orphanet: an online rare disease and orphan drug data base. Subcortical band heterotopia. ORPHA:99796

A rare, non-syndromic cerebral malformation due to abnormal neuronal migration characterized by variable clinical manifestation depending on the location, size and thickness of subcortical bands. Clinical presentation ranges from mild cognitive deficit to developmental delay with severe intellectual disability, seizures and behavioral problems. 